\title{
FIBRINOGEN AND THE SLIDE COAGULASE TEST
}

\author{
BY \\ J. G. C. SPENCER \\ From Frenchay Hospital, Bristol
}

(RECEIVED FOR PUBLICATION JULY 31, 1953)

The advantages of using solutions of fibrinogen instead of plasma for carrying out the slide coagulase test were pointed out by Berger (1943) when he showed that their use avoided false positives due to naturally occurring staphylococcal agglutinins in rabbit and human plasma, in addition to the fact that these solutions retained their activity considerably longer. Using fibrinogen he demonstrated as complete a correlation between the slide and the tube method as had already been shown to exist between the two tests by BirchHirschfeld (1934) and Cadness-Graves, Williams, Harper, and Miles (1943) when fresh plasma is used for both tests. Berger prepared his solution from fresh citrate plasma by half saturation with sodium chloride for four hours in the ice chest, and dissolving the precipitate in sterile water to the volume of plasma originally taken.

While such preparations give good results and may retain their activity for several weeks if kept in the refrigerator, they tend to become infected with constant use, thereby losing their activity, and after being in use for a week or two they often become cloudy from precipitation of fibrinogen or its degradation products and the results of the test may be difficult to observe. The addition of a small crystal of thymol does not appear to interfere with the coagulase reaction and does seem to delay the onset of infection even if it does not stop the cloudiness and denaturation of the fibrinogen. Lastly, difficulty may be encountered at times with the precipitation of the fibrinogen, which may be delayed or incomplete.

\section{Method}

For over a year this laboratory has prepared and stored solutions of crude fibrinogen for the slide coagulase test by the following method:-

Plasma is one-fifth saturated with ammonium sulphate, and precipitation is usually complete at room temperature in from 10 to 15 minutes. The precipitate is then firmly thrown down by centrifuging at 2,500 r.p.m. for five minutes. The supernatant is poured off and the universal container allowed to drain for a few minutes, inverted on filter paper. The precipitate is then taken up in $10 \%$ aqueous urea to? a volume roughly the same as the volume of plasma. $\checkmark$ originally taken. The three stages of precipitation, $\vec{r}$ centrifugation, and final solution and storage can be + conveniently carried out in the same $20-\mathrm{ml}$. universalo container. This gives a preparation faintly opalescentor as clear as water, and when it is brought into use 7 the screw cap is replaced by a similar one penetratedo by a teated glass pipette drawn out to a fine point for? ease in delivering single drops on to the slide.

The source of plasma is usually the centrifuged, unused remains of blood from the bottom of trans- -0 fusion bottles. Where this is not readily available, the + method outlined here can be equally well applied to the unused remains of oxalated blood used fore haematological or biochemical investigations, fluorides plasma for blood sugar estimation, or reconstitutedo plasma. Such specimens often require to be clearedô of blood cells, debris, or fat, and the centrifuge may@ fail to do this, especially when dealing with samples $\overrightarrow{\vec{A}}$ of reconstituted plasma, but it may be satisfactorily응 carried out by Seitz filtration using a clearing pad. Duthie and Lorenz (1950) showed that this manoeuvre also removes most of the prothrombin but not fibrinogen or undue amounts of the accelerator factor, whicho was found by Smith and Hale (1944) to combine with:staphylocoagulase to form a substance which will then 3 convert fibrinogen to fibrin in the absence of calcium or thrombin. Such solutions will retain their activityo for at least one month if kept on the bench away from direct sunlight, and for upwards of five months음 when stored in the refrigerator.

\section{Storage}

The use of aqueous urea as a solvent and for storage follows the observations of Meissner and Wöhlisch $\tilde{O}$ (1937), who refer to its effect on solutions of fibrinogen N as a protective influence, and it is possible that the two substances form a loosely bound compound. In confirming this work, Diebold and Jühling (1938) found that although denaturation of fibrinogen does proceed in $10 \%$ urea, it is very slow, especially at ${ }^{+}$ $4^{\circ} \mathrm{C}$., and the urea is considered by them as a preservative of the fibrinogen. Lastly, the denaturation products stay in solution so that the preparation retains $\Omega$ its clarity while continuing to give a prompt clumping $\mathbb{\mathbb { Q }}$ reaction with pathogenic staphylococci independently of the source of plasma used in the first instance. We have also found that $10 \%$ urea has a sufficiently strong 
antibacterial action to suppress almost all accidental infection of the solution.

To demonstrate this, 2-ml. lots of fibrinogen in $10 \%$ urea were seeded separately with Staphylococcus aureus (Oxford) at $13 \mathrm{~m}$. organisms per ml., Bacterium coli at $17 \mathrm{~m}$. organisms per ml., and Bacillus subtilis at $6 \mathrm{~m}$. organisms per ml. Tubes were left on the bench at room temperature, which varied between $24^{\circ} \mathrm{C}$. and $27.5^{\circ} \mathrm{C}$., and subcultures made at eighthour intervals. Up to 24 hours subcultures showed heavy growth in all tubes, but after 72 hours all tubes seeded with Staph. aureus and with B. subtilis were sterile and those seeded with Bact. coli gave only isolated colonies after heavy inoculation of a blood agar plate. Finally it was found that all these tubes retained their coagulase activity apparently unimpaired at the end of this experiment.

\section{Discussion}

Attention has been drawn to these methods of preparing and storing fibrinogen because of the increasing use of the slide coagulase test that naturally follows the recent re-classification of the aerobic, catalase-positive, Gram-positive cocci by Shaw, Stitt, and Cowan (1951) at the National Collection of Type Cultures. These authors have not only confirmed the findings of previous writers from Cruickshank (1937) onwards that the demonstration of staphylocoagulase is the most reliable single criterion of pathogenicity in staphylococci, but they have made it a dominant feature of the classification, outmoding such criteria as pigment formation. Dealing with this feature alone, they find that $25 \%$ of pathogenic strains produce no pigment, while gold and yellow pigments are found in $38 \%$ and $7 \%$ of non-pathogenic strains. In this respect the now recognized disturbing effect of antibiotics on pigment production is particularly relevant, for organisms that have been subject to antibiotics are among the commoner strains of staphylococcus met with in hospital work to-day.

While the tube coagulase reaction will remain the more delicate test if done under standard conditions, the slide coagulase reaction is a valuable screening one and essential when as many as 20 strains of staphylococci may be encountered in the course of a morning's work. The use of crude fibrinogen solutions appears to be more than an interesting application of the original observations of Loeb (1903) and Much (1908), and has a special interest for those laboratories which have no ready access to an animal house, or where the amount of haematological work may not make available sufficient daily amounts of fresh plasma for a relatively large bacterial department.

\section{Summary}

A modification of Berger's method is described for the preparation of crude fibrinogen for the slide coagulase test, using ammonium sulphate for precipitation and aqueous urea as a reagent with better solvent and keeping qualities.

The literature is briefly reviewed.

I am indebted to Dr. W. A. Gillespie of the Bristol Royal Infirmary for helpful criticism and advice.

\section{REFERENCES}

Berger, F. M. (1943). J. Path. Bact., 55, 435

Birch-Hirschfeld, L. (1934). Klin. Wschr., 13, 331

Birch-Hirschfeld, L. (1934). Klin. Wschr., 13, 331. (1943). Lancet, 1, 736.

Cruickshank, R. (1937). J. Path. Bact., 45, 295.

Diebold, W., and Jühling, L. (1938). 'Biochem. Z., 296, 389.

Duthie, E. S., and Lorenz, L. (1950). Nature, Lond., 165, 729.

Loeb, L. (1903). J. med. Res., 10, 407.

Meissner, I., and Wöhlisch, E. (1937). Biochem. Z., 293, 133.

Meissner, I., and Wöhlisch, E.

Shaw, C., Stitt, J. M., and Cowan, S. T. (1951). J. gen. Microbiol., $5,1010$.

Smith, W., and Hale, J. H. (1944). Brit. J. exp. Path., 25, 101. 